\title{
OBSERVATION OF THE WHITE LIGHT CORONA FROM A STRATOSPHERIC BALLOON $\left({ }^{1}\right)$
}

\author{
By Gordon NwwkrRK, Jr. and J. David BoHrin \\ (High Altitude Observatory, Boulder, Colorado, U. S. A.)
}

Résomt. - On a pu réduire la lumière diffusée dans un coronographe à $10^{-9} B_{\odot}$ en utilisant un disque occultan apodisé placé en avant de l'objectif. Des jets coronaux s'étendant jusqu'à $1,8 R_{\odot}$ et $5,25 R_{\odot}$ ont pu être ainsi observés $\grave{a}$ bord d'un ballon à $30 \mathrm{~km}$ d'altitude. Un ensemble de jets coronaux présent sur le limbe ouest, le 5 mars 1964, semble avoir constitué la source des particules qui ont causé les tempêtes géomagnétiques récurrentes de la fin 1963 et du début 1964.

ABSTRACT. - By use of an apodized occulting disk before the objective lens of a coronagraph the instrumentally scattered light can be reduced to about $10^{-9} B_{\odot}$. Observation of the streamers of the solar corona from 1.8 to $5.25 R_{\odot}$ outside of eclipse from a balloon at $30 \mathrm{~km}$ altitude are described. A solar streamer complex present at the west limb on 5 March 1964 was apparently the origin of the particles causing the recurrent geomagnetic storms of late 1963 and early 1964.

Резюме. - Удалось привести дифффузированный в коронографе свет до 10- в $\odot$ используя блуждающий затемняющий, диск расположенный впереди обвектива. Корональные струи, простирающиеся до $1,8 \mathbf{R}_{\odot}$ и $5,25 \mathbf{R}_{\odot}$, смогли таким образом быть наблюдены с борта воздушного шара на высоте 30 км. Совокупность корональных струй, имевпаяся на западном лимбе 5 марта 1964 г, по видимому была источником частиц произведших повторные геомагнитные бури в конце 1963 и вачале 1964 г.

\section{INTRODUOTION.}

The essential problem which must be overcome if the corona is to be observed outside of solar eclipse is that of the low contrast of the corona above the background of skylight and instrumentally scattered light (Fig. 1). The most common solution of the problem - spectrographic isolation of the brighter emission lines of the corona - allows the contrast to be increased by one or two orders of magnitude at the limb of the Sun. However, the sharp gradient of the radiance of the emission lines with height above the solar limb prevents examination of the intermediate and outer corona by this technique. $\mathrm{K}$-coronameters [2, 3 and 4], which take advantage of the polarization of the $\mathrm{K}$-corona to extract the minute coronal signal from the sky background, have been able to detect coronal streamers well above the limb of the Sun. However, the polarization and the inevitable temporal variations present in the sky radiance prevent such instru-

(1) This research has been supported by the Office of Naval Research, the National Science Foundation, and National Aeronautics and Space Administration. ments from detecting the corona much above $2 \mathrm{R} \odot$. The advent of stratospheric balloons and rockets has created the opportunity for the observation of the intermediate and outer solar corona outside of eclipse. Figure 1 clearly shows that the atmospheric background can be sufficiently reduced by observing from altitudes in excess of $30 \mathrm{~km}$ in the near infrared to allow straightforward detection of the corona out to about $5 \mathrm{R} \odot$. Clearly, if the advantage of near space or space observation of the corona is to be realized, the radiance of light scattered in the coronagraph must be reduced by nearly three orders of magnitude from that found in the Lyot coronagraph.

\section{INSTRUMENT.}

Evans [5] was the first to describe a coronagraph employing an external occulting disk which prevents direct photospheric radiation from striking the objective lens. Two flights of such a coronagraph [6, 7, and 8] on a balloon to $25 \mathrm{~km}$ for the purpose of measuring the radiance of the sky demonstrated that instrumentally scattered light of about $10^{-8} \mathrm{~B} \odot(\mathrm{B} \odot$ is the radiance of 


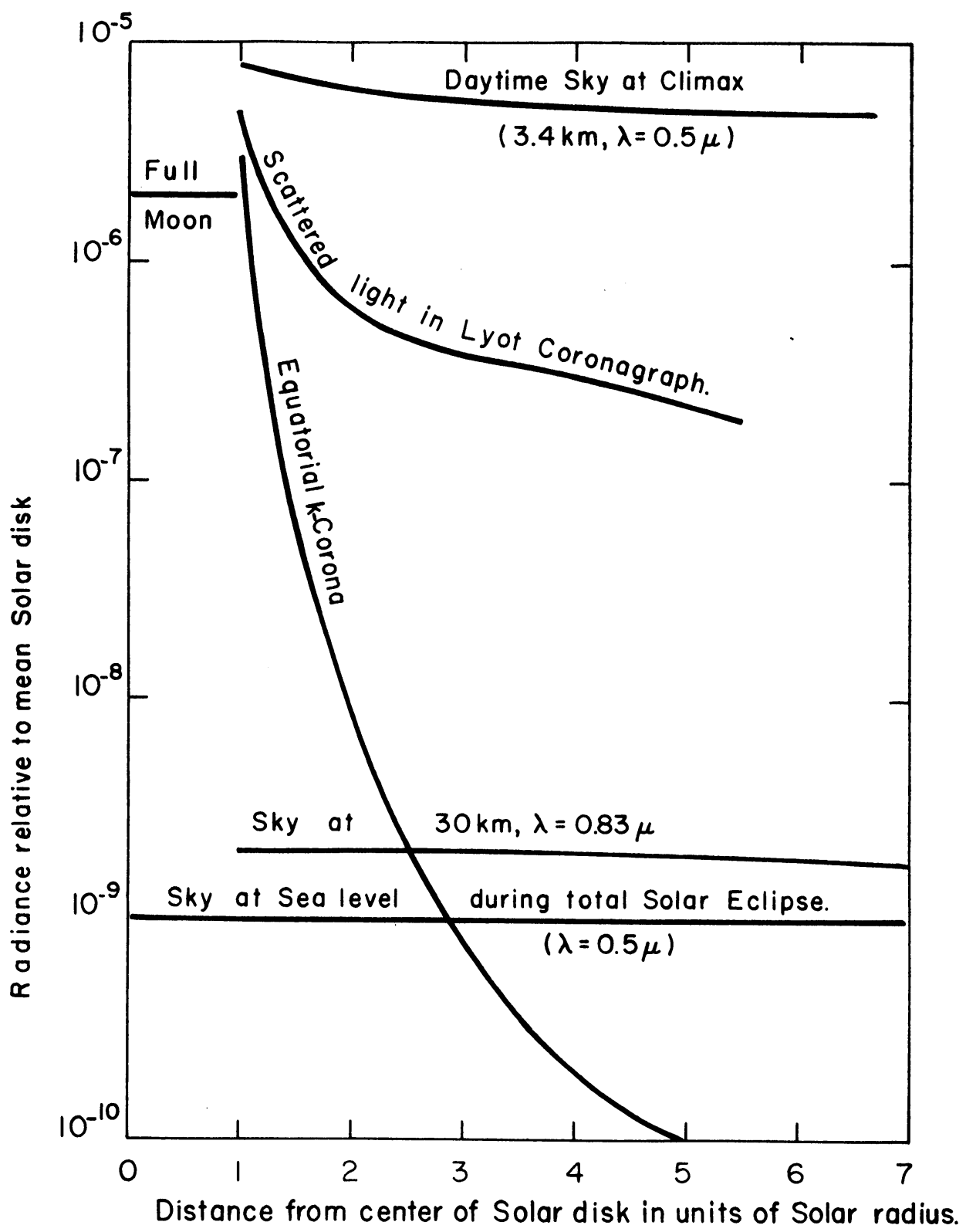

Fra. 1. - Comparison of the radiance of the equatorial K-corona [1] with that of several sources of background radiation. The unit of radiance is that of the mean solar disk at the wavelength considered.

the mean solar disk at the wavelength considered) prevents all but marginal detection of the corona. Diffraction from the external occulting disk is the main source of this stray light.

The light diffracted into the objective may be reduced by removing the occulting disk to a great distance, as is the moon at total eclipse, or by "apodizing" or " softening " the edge of the disk. (Although " apodization" commonly refers to the alteration of the Fraunhofer diffraction pattern of an objective lens by means of a radially graded filter $[9,10]$, it is here used to describe the modification of the Fresnel diffraction by an opaque disk.) The serrated occulting disk developed by our colleagues at the Naval Research Laboratory [11] is one form of apodization. A second, although presently impractical, form is a radially graded filter which varies smoothly from completely opaque at the edge of the occulting disk to completely transparent at a larger radius. Coronascope II employs a different method of apodization, three occulting disks in a line [12] in which each disk prevents radiation diffracted from its sunwards predecessor from reaching the 


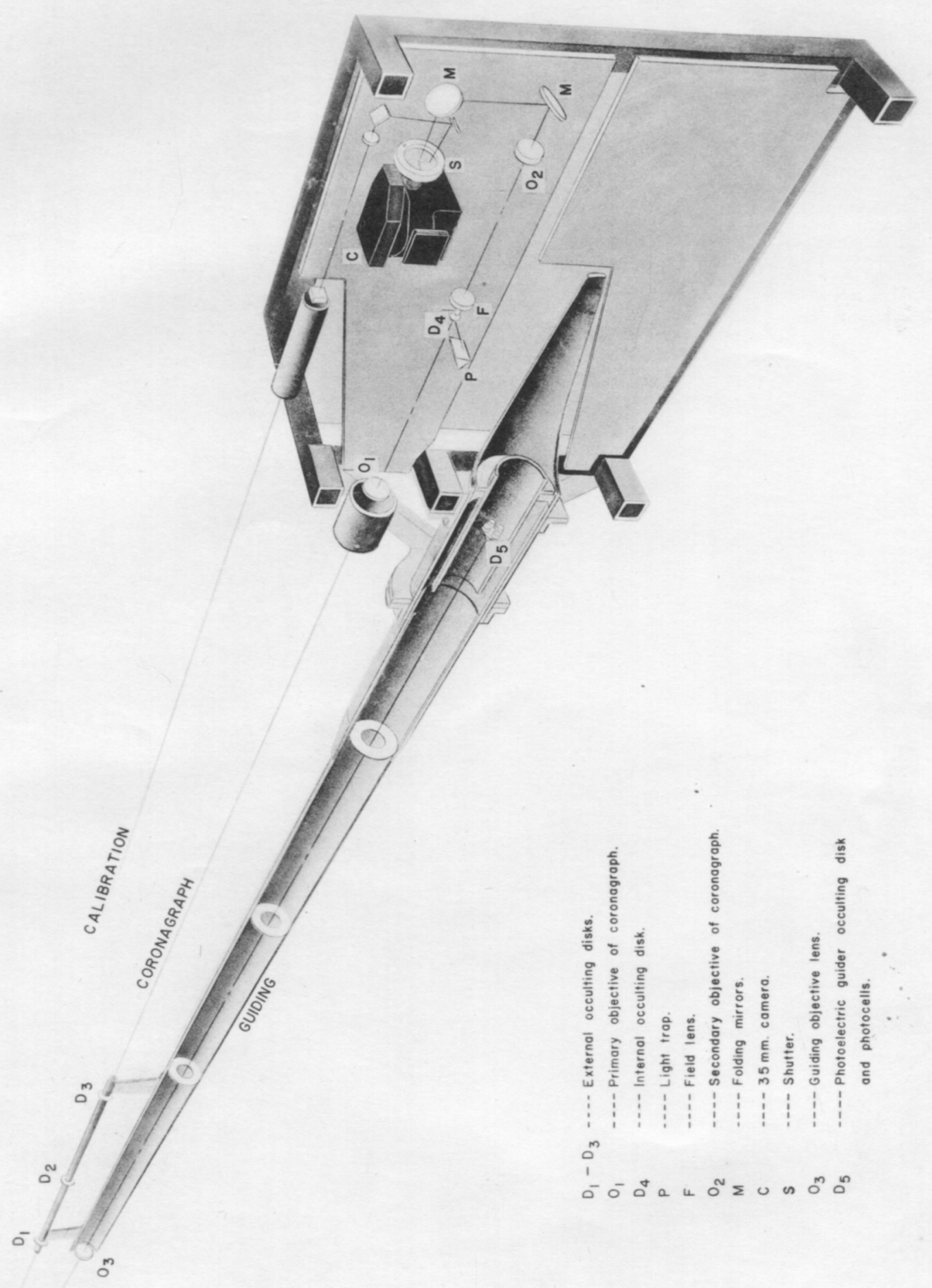




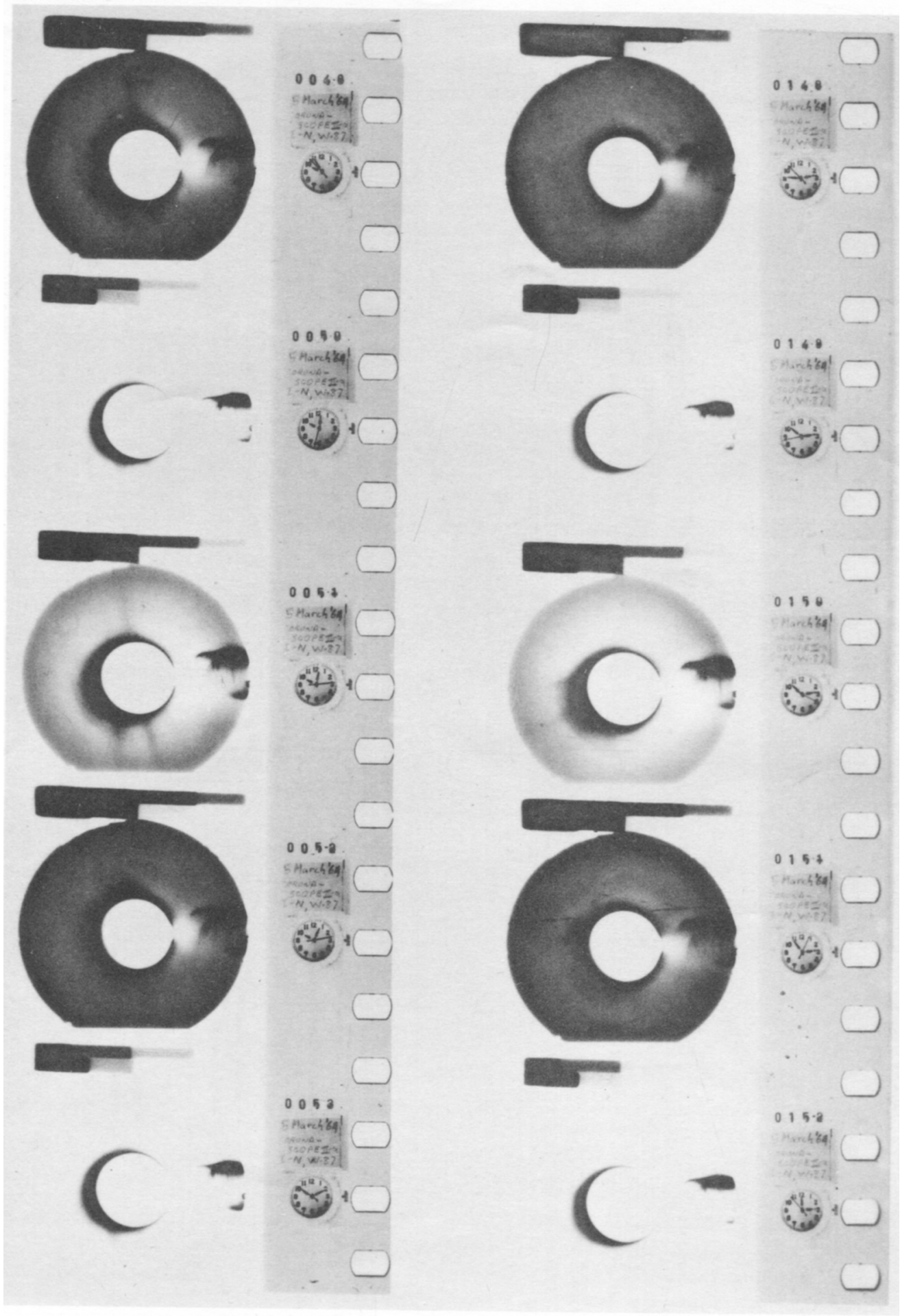

Fig. 3 - Photographs (negative) of the white light corona from 1,8 to $5,25 R_{0}$ from center of the solar disk. The effective wavelength is $8300 \mathrm{~A}$ and the angular resolution, about 14 seconds of arc. Exposure times were 30: 100: and 300 . Note the diurnal rotation of the coronal streamers between the $16: 00$ UT (10:00 CST) strip at the left and the 21 : 00 UT (15:00 CST) strip at the right. 


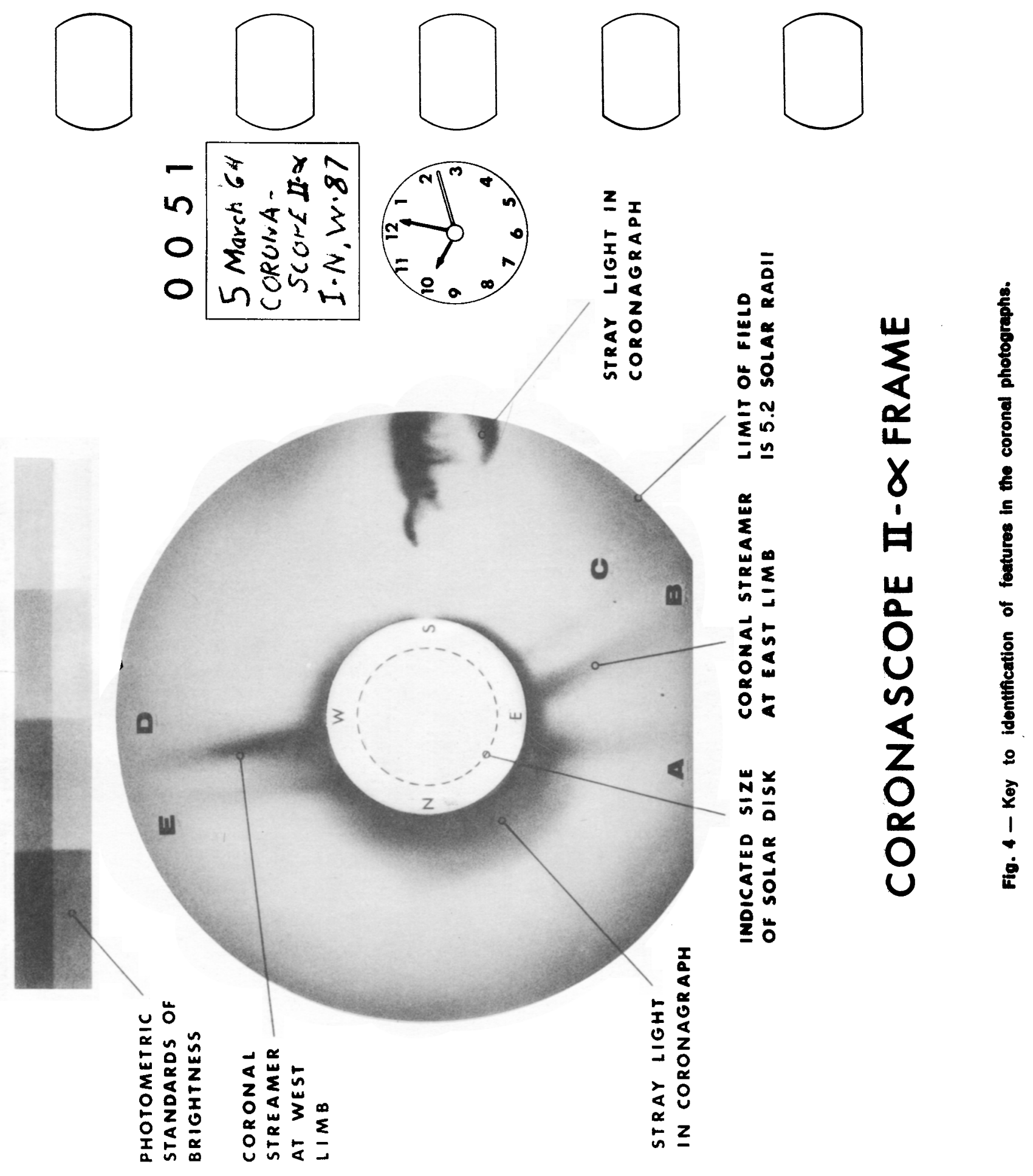




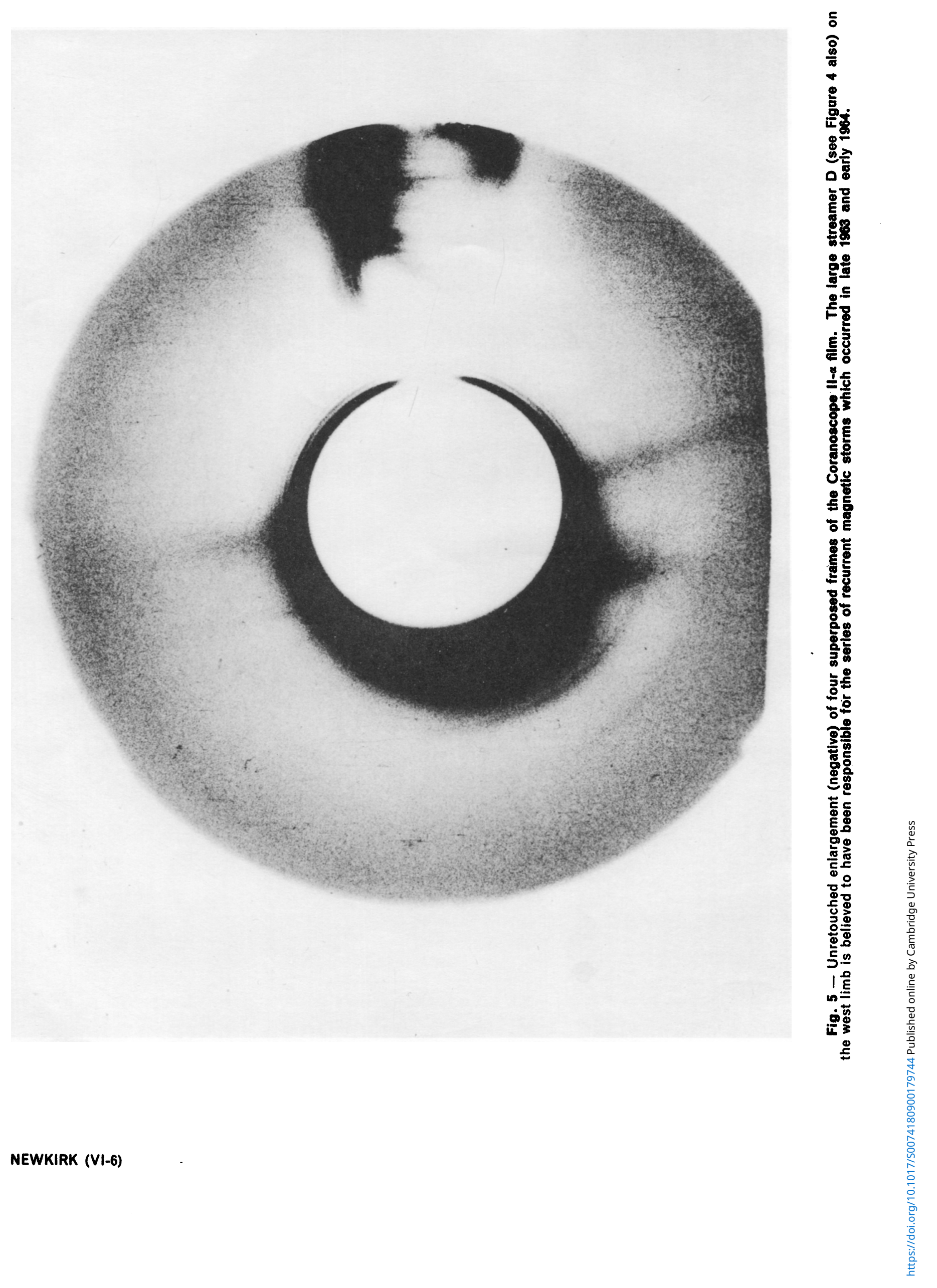




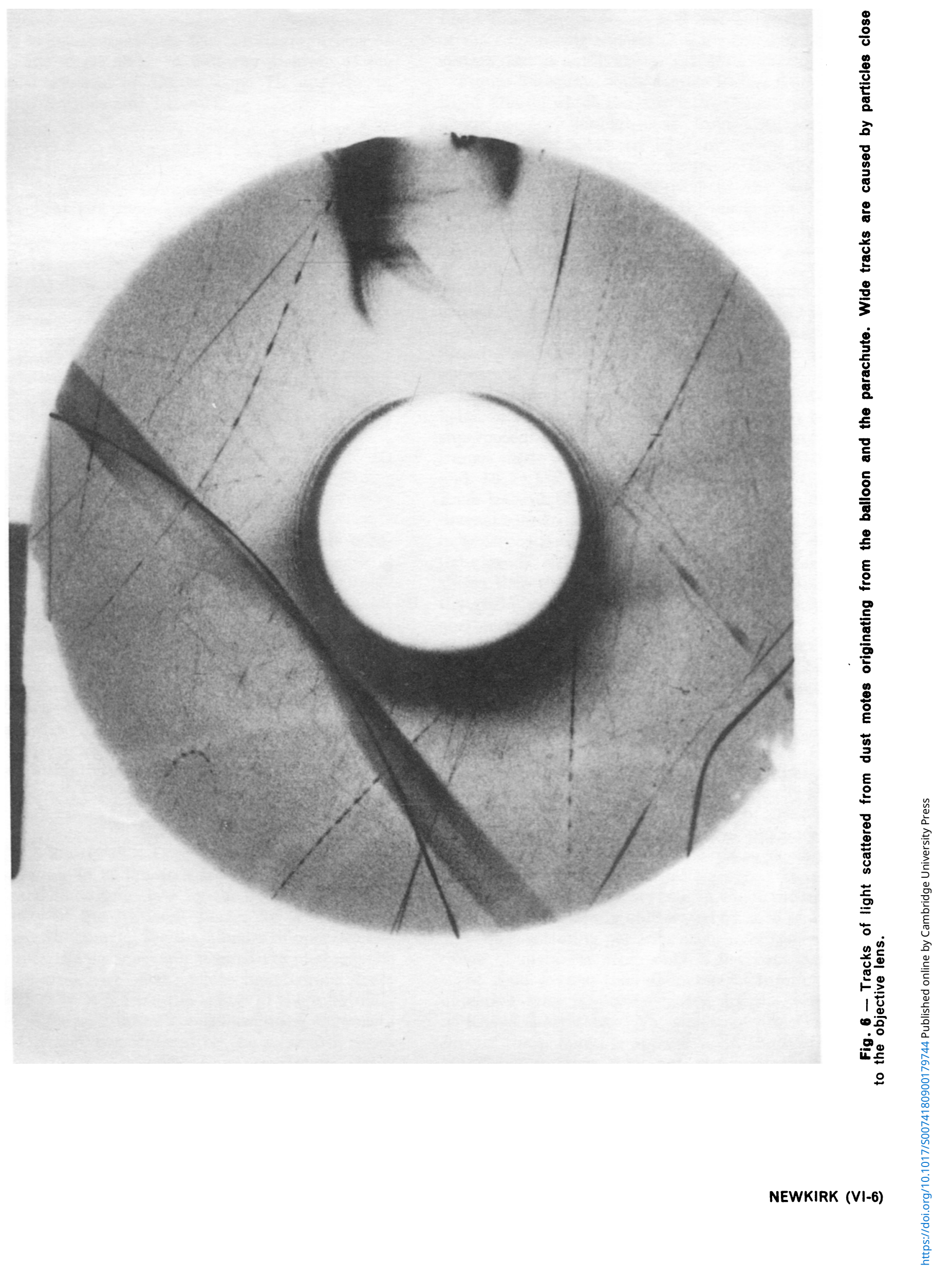


objective lens. Laboratory tests have shown that such an occulting scheme diffracts only about $1 / 13$ as much light into the coronagraph lens as does the single disk. A cutaway diagram of the optical system of Coronascope II appears in Figure 2. (See also Table I),

\section{TABLE I}

Dimensions

of the Coronascope II System

\begin{tabular}{lc}
\hline \hline Objective aperture & $3.2 \mathrm{~cm}$ \\
Occulting disks : & \\
$\quad$ diameter $\mathrm{D}_{1}$ & $5.528 \mathrm{~cm}$ \\
$\quad$ diameter $\mathrm{D}_{2}$ & $5.325 \mathrm{~cm}$ \\
$\quad$ diameter $\mathrm{D}_{3}$ & $5.121 \mathrm{~cm}$ \\
Separation $\mathrm{D}_{1}$ to $\mathrm{O}_{1}$ & $229.0 \mathrm{~cm}$ \\
Separation $\mathrm{D}_{1}$ to $\mathrm{D}_{2}$ and $\mathrm{D}_{2}$ to $\mathrm{D}_{3}$ & $20.0 \mathrm{~cm}$ \\
Effective wavelength & $0.83 \mu$ \\
Image scale & $598 \mathrm{sec}$ arc/mm \\
Image resolution (measured) & $14 \mathrm{~s} \mathrm{arc}$ \\
Scattered light level & $1.1 \times 10^{-9} \mathrm{~B} \odot$ \\
Weight (coronagraph alone) & $120 \mathrm{~kg}$ \\
\hline \hline
\end{tabular}

The radiance of scattered light in this coronagraph has been evaluated in the $\mathbf{4 9}$ meter long vacuum tunnel of the Kitt Peak National Observatory using a carbon arc and a $12.7 \mathrm{~cm}$ diameter lens as a "synthetic sun". With the tunnel evacuated to $1 \mathrm{~mm}$ of mercury and the projection lens subtending an angle of 32 minutes of arc from the coronagraph, we have found [13] the radiance of stray light to be $1.1 \times 10^{-9} \mathrm{~B} \odot$. Thus, stray light in this coronagraph contributes about as much background as does the sky at sea level during total solar eclipse.

\section{Observations.}

On 5 March 1964 Coronascope II ascended to an altitude of $30 \mathrm{~km}$ on a $10^{5}$ cubic meter, Mylarscrim balloon launched by the Scientific Balloon Facility of the National Center for Atmospheric Research. During the 5-1/2 hours of operation at altitude, the coronagraph secured 118 photographs of the streamers of the white light corona from 1.8 to $5.25 \mathrm{R} \odot$ from the center of the solar disk. Except for an interval about local noon, the entire coronagraph was centered on the solar disk to an accuracy of \pm 5 seconds of arc, maximum excursion. Guiding was performed by a modified version of the old Stratoscope I $[14,15,16]$ bi-axial pointing control. A popular description of the flight has been published [17] and an evaluation of the engineering aspects of the guiding, control system, etc. is available for private circulation.

Figure 3 displays some sample frames from the flight film on which the coronal streamers may be unequivocally distinguished from artifacts of instrumentally scattered light by means of the diurnal rotation of the streamers. The obvious vignetting of the central part of the field of Figure 3 is a rather accidental consequence of all externally occulted coronagraphs, which produce a most welcome reduction in the steep gradient of coronal radiance with distance from the Sun. The horseshoe of scattered light in the frame was caused by a slight misalignment of the internal occulting disk. A key by which the various features of the photograph may be identified appears in Figure 4.

In an effort to increase the relative contrast between the corona and the background, we have superposed four transparent enlargements of frames made at 15.44 UT, 15.52 UT, 16.01 UT, and 16.14 UT with 30 second exposure times. Each transparency was rotated by the calculated diurnal rotation so that coronal features appeared in superposition while random features and stray light were reduced in effectiveness. Figure 5 shows that this technique does, in fact, improve the visibility of the coronal streamers although it also enhances the circularly symmetrie artifacts of stray light. Although the complete analysis of these photographs for the radiance of the K-corona is not complete, a preliminary reduction shows the equatorial coronal streamer $\mathbf{D}$ to have a radiance close to that expected for a sunspot minimum corona [1].

Another source of background scattering also must be discussed. Of the 118 coronal photographs made during the 5-1/2 hours of operation, approximately half showed some evidence of streaks of light caused by the passage of dust motes in front of the coronagraph. Figure 6 shows a frame, fortunately rare, in which the image of the corona is nearly obliterated by such streaks. That the scattering particles occur over the entire range of distances from only a few centimeters to at least several tens of meters in front of the objective lens is demonstrated by the various widths of the tracks. No consistent direction of flow of the particles is apparent. Although there is little doubt that these particles originate from the balloon, the parachute, and the gondola, they should warn us that a similar cloud of dust may 


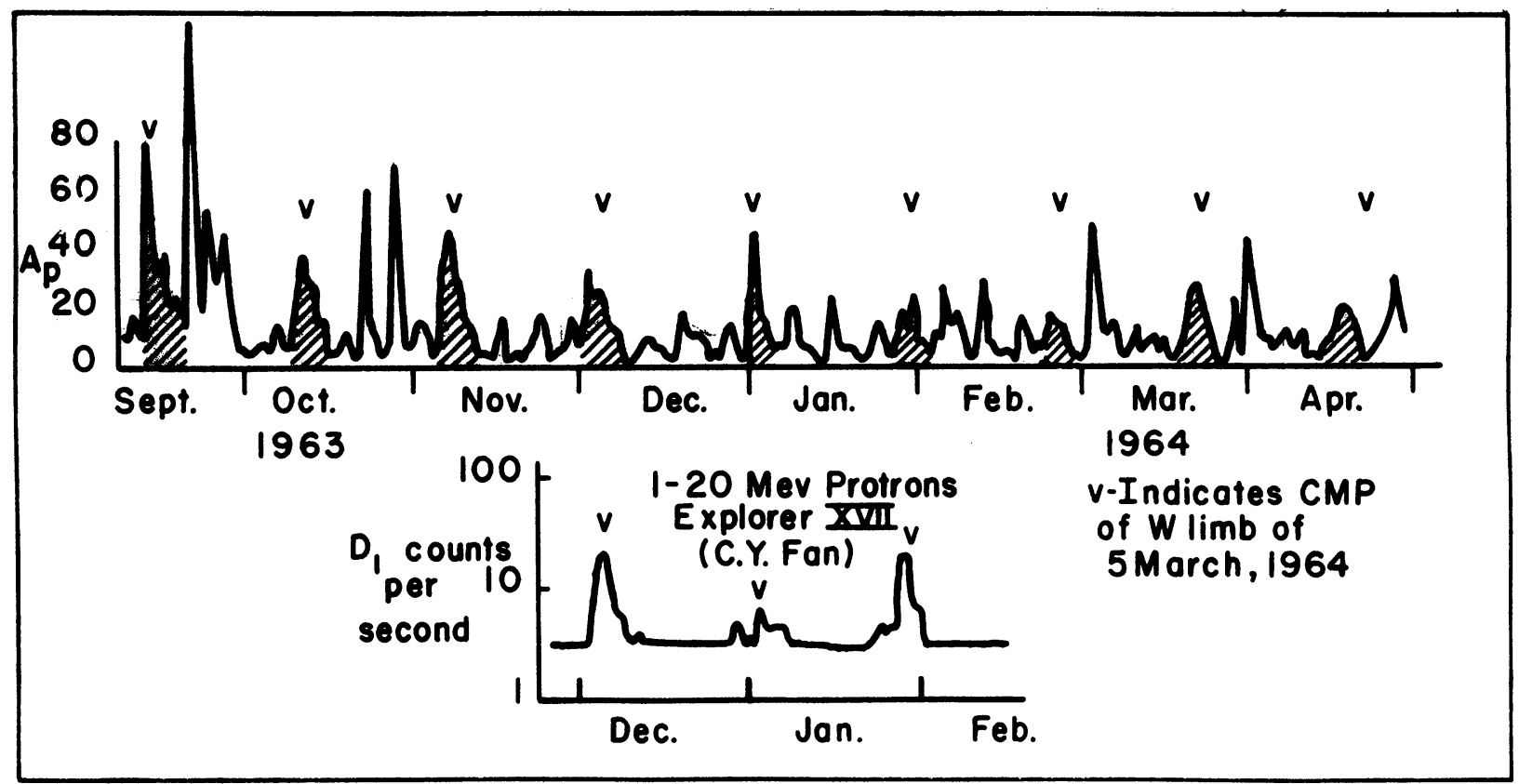

Fra. 7. - Geomagnetio oharacter figure $A p$ and the counts of 1-20 MeV protons (courtesy FaN, GLOROKnRR, and Simpson) during late 1983 and $\theta$ zrly 1981 . Apparently the streamor joomplex D.E was responsible for the precurrent magnetio storm (shaded) and the proton events.

prevent the efficient operation of satellite and rocket borne coronagraphs. Indeed, such a pattern of dust tracks has already been observed from a rocket [18]. Unfortunately, particles surrounding a satellite would be removed at only a very slow rate by radiation pressure and aerodynamic drag.

By a fortunate accident the first flight of Coronascope II occurred during a long series of recurrent geomagnetic storms. As is shown in Figure 7 the geomagnetic phase of the disturbance was also accompanied by the incidence of 1-20 MeV protons as detected by the satellite Explorer XVII (courtesy Far, GLOEOKLER and SIMPson). As evidence that streamer complex D-E was the source of these particles, we show also the date of central meridian passage of the west limb of 5 March 1964 in Figure 7. The fact that the storms recurred approximately on the date of central meridian passage of the west limb of 5 March suggests that the source of the disturbance had already passed beyond the west limb by 2-3 days on the date of our coronal observation. Although it is impossible to infer the longitude of the streamer complex D-E, its identification with the magnetic storm and the channelling of the high energy protons seems probable. As additional evidence we note that the brighter streamer (D) lay in the plane of the ecliptic during its central meridian passage.

\section{REFERENCES}

[1] Aluen C. W., 1955, Astrophysical Quantities, Athlone Press, p. 143.

[2] Wlarick G. and Axteril J., 1957, Ap. J., 126, 253.

[3] Dollfus A., 1958, C. R., 246, 2345.

[4] NewkIRK G.; Curtis G. W. and Watson K., 1958, IGY Solar Activity Report Series No. 4.
[5] Evans J. W., 1948, JOSA, 38, 1038.

[6] NWWKIRK G. and EdDY J. A., 1962, Nature, 194, 638.

[7] Newkirk G. and Eddy J. A., 1962, Sky and Telescope, 24, 77.

[8] Newkirk G. and EdDy J. A., 1964, J. Atm. Sci., 21, 35. 
[9] RoIzen-Dossirer B., 1956, Astronomical Optics and Related Subjects, Z. Kopal ed., North Holland, Amsterdam, p. 16.

[10] BarAkAt R., 1962, JOSA, 52, 264.

[11] Pukomll J. D. and Koomen M. J., paper presented at Spring Meeting, Optical Society of America, 14-17 March 1962.

[12] Newkirk G. and BoHLIN J. D., 1963, App. Opt., 2, 131 .
[13] Newkirk G. and BoHLIN J. D., 1964, App. Opt., $3,543$.

[11] Rogerson J., 1958, Sky and Telescope, 17, 112.

[15] SoHWARZSOHIDD M. and SchwarzSOHID B., 1959, Sci. Amer., 200, 52.

[16] Danimlson R. E., 1961, Ap. J., 134, 275.

[17] NewkiRK G. and BoHLIN J. D., 1964, Sky and Telescope, 28, 16.

[18] Tousey R., IAU Symposium No 23, p. 293. 